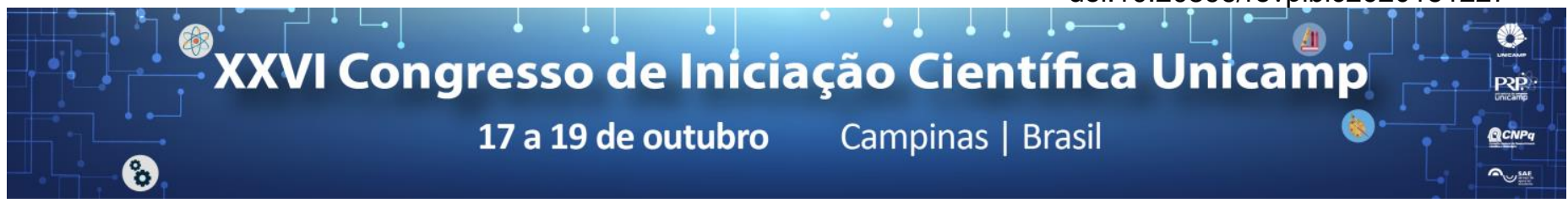

\title{
Extração assistida por ultrassom de antioxidantes presentes em chá preto (Camellia sinensis)
}

\section{Aluno: Rodrigo Stein Pizani. Orientador: Mauricio Rostagno. Mariana Corrêa de Souza}

\section{Resumo}

A Camellia sinensis é a planta mais usada para produção de chás nos dias atuais. O método de extração utilizado na preparação dos chás exerce grande influência no teor de substâncias extraídas, em especial os teores de compostos fenólicos e cafeína. No presente estudo, amostras de chá preto tiveram processo de extração analisado frente aos solventes água e solução de etanol $50 \%$, às temperaturas de $40^{\circ} \mathrm{C}, 50^{\circ} \mathrm{C}, 60^{\circ} \mathrm{C}$ e sob as frequências de ultrassom de $37 \mathrm{kHz}$ e $80 \mathrm{kHz}$. O teor de compostos extraídos foi quantificado pelos métodos FRAP (potencial antioxidante para reduzir sal férrico), TEAC (capacidade antioxidante do equivalente trolox) e fenólicos totais.

Palavras-chave: Extração; Ultrassom; Fenólicos.

\section{Introdução}

Os compostos fenólicos são metabólitos secundários de plantas, sintetizados numa ampla variedade de formas e por diversos tecidos vegetais. São encontrados inclusive em vários alimentos, como frutas, legumes, cereais, vinhos, chás e café [1].

Estudos epidemiológicos têm demonstrado relação direta entre o consumo de chá e a redução do risco de doenças cardiovasculares e câncer, efeito atribuído aos compostos polifenólicos presentes na planta [2].

A presença do anel conjugado e grupos hidroxila dessas substâncias conferem a capacidade de aceitar ou inativar radicais livres [3]. Seu mecanismo de ação inclui capacidade de sequestrar espécies reativas de oxigênio, capacidade de sequestrar eletrófilos, capacidade de inibir nitrosação, capacidade de quelar metais e capacidade de modular a atividade de algumas enzimas e vias de sinalização celular [2].

Estudos demonstram que a aplicação de ultrassom no meio de extração aumenta o rendimento do processo nos mais variados tipos de matérias-primas como, por exemplo isoflavonas de soja [4].

\section{Resultados e Discussão}

As amostras de chá preto tiveram processo de extração analisado frente aos solventes água e solução de etanol $50 \%$, às temperaturas de $40^{\circ} \mathrm{C}, 50^{\circ} \mathrm{C}, 60^{\circ} \mathrm{C}$ e sob as frequências de ultrassom de $37 \mathbf{~ k H z ~ e ~} 80 \mathbf{~ k H z}$.

$\mathrm{O}$ teor de compostos extraídos foi quantificado pelos métodos FRAP (potencial antioxidante para reduzir sal férrico), TEAC (capacidade antioxidante do equivalente trolox) e fenólicos totais.

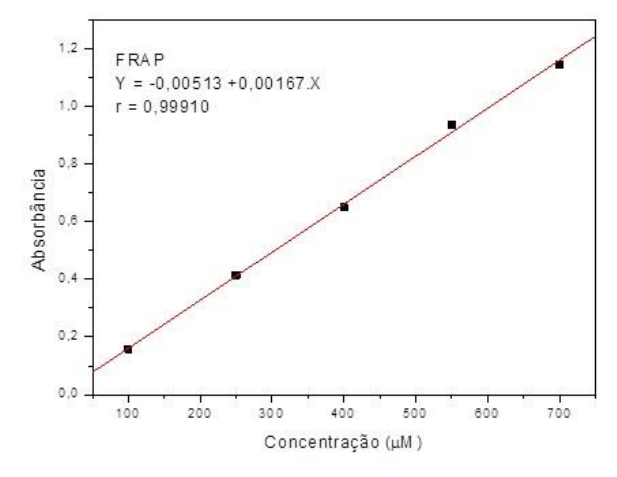

Figura 1. Exemplo de regressão linear para FRAP
Analisou-se também o perfil geral das amostras em HPLC (cromatografia líquida de alta eficiência), com auxílio de aluno de mestrado*, revelando que os extratos se constituem majoritariamente de ácido gálico, cafeína e flavonoides como quercetina, mirecetrina e keampferol.

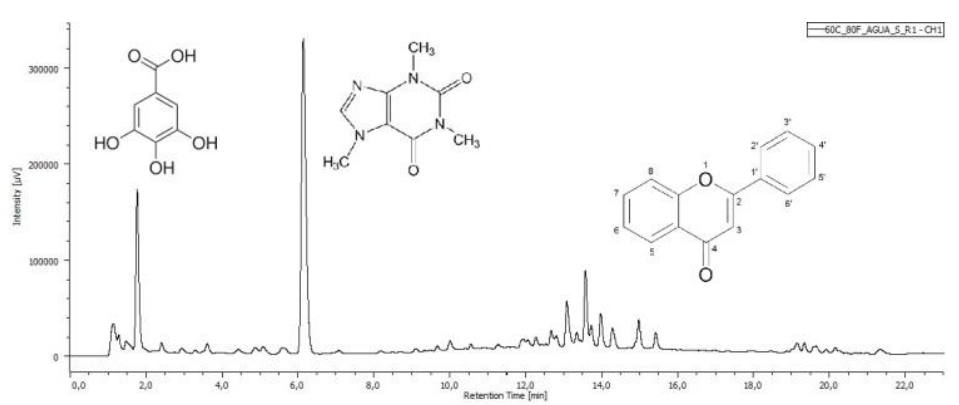

Figura 2. Cromatograma e estruturas envolvidas.

\section{Conclusões}

A condição de extração com maior destaque foi etanol $50 \%, 60^{\circ} \mathrm{C}$ e $37 \mathrm{kHz}$, com FRAP de $1,9 \times 10^{4} \mu \mathrm{M} \mathrm{FeSO}_{4}$, TEAC de $2,0 \times 10^{4} \mu \mathrm{M}$ Trolox e fenólicos totais de $2,1 \times 10^{3}$ $\mu \mathrm{g} / \mathrm{mL}(\mathrm{ppm})$, seguida por etanol $50 \%, 50^{\circ} \mathrm{C}$ e $37 \mathrm{kHz}$, com FRAP de $1,8 \times 10^{4} \mu \mathrm{M} \mathrm{FeSO} 4$, TEAC de $1,9 \times 10^{4} \mu \mathrm{M}$ Trolox e fenólicos totais de $2,3 \times 10^{3} \mu \mathrm{g} / \mathrm{mL}$ (ppm). Os extratos se constituem majoritariamente de ácido gálico, cafeína e flavonoides como quercetina, mirecetrina e keampferol.

\section{Agradecimentos}

Agradeço à Mariana Correa* pelas orientações e cromatogramas. Ao meu orientador Mauricio Rostagno e a todos do laboratório LAPFAL.

[1] FARAH, A.; DONANGELO, C.M. Phenolic compounds in coffee. Brazilian Journal of Plant Physiology, Londrina, v.18, n.1, p.23-63, 2006.

[2] DAMODARAN, Srinivasan. Química de alimentos de Fennema Coautoria de Owen R. Fennema, Kirk Parkin; Tradução de Adriano Brandelli. 4. ed. Porto Alegre, RS: Artmed, 2010. 900 p.

[3] OETTERER, Marília. Fundamentos de ciência e tecnologia de alimentos. Coautoria de Marisa Aparecida Bismara Regitano-D'arce, Marta Helena Fillet Spoto. Barueri, SP: Manole, 2006. 612 p.

[3] Rostagno, M. A., PALMA, M., \& BARROSO, C. G.. Ultrasoundassisted extraction of soy isoflavones. Journal of Chromatography A, 1012(2), 2003, 119-128. 